\title{
Number and affinity of insulin receptors in intact human subjects
}

\author{
R. H.Jones ${ }^{1}$, P. H.Sönksen ${ }^{1}$, M. A. Boroujerdi² and E. R. Carson ${ }^{2}$ \\ ${ }^{1}$ Department of Medicine, St Thomas' Hospital Medical School, and \\ ${ }^{2}$ Department of Systems Science, The City University, London, UK
}

Summary. A simple model of the distribution and metabolism of insulin in vivo has been evaluated using data from insulin infusion into a group of normal subjects. The major rate-limiting step for access to degradation pathways is assumed to consist of binding of the ligand to a single population of insulin receptor sites, except that provision is made for the possibility of linear non-receptor-mediated degradation and for the phenomenon of negative cooperativity. The model has been shown to accommodate the non-linearity of insulin metabo- lism, allows evaluation of receptor association and dissociation constants and provides for the first time an estimate of total accessible receptor number in the intact organism. For normal fasting man the model predicts $1.00 \pm 0.05$ nmol accessible binding sites $/ \mathrm{kg}$ (mean $\pm \mathrm{SD}$ ).

Key words: Insulin binding, insulin metabolism, receptor, compartmental analysis, degradation.
Rapid removal of insulin from the circulation leading to the appropriate reduction in the hormone's biological signal is an essential component of the physiology of substrate homeostasis.

Recently there has been increasing recognition that insulin receptors themselves may play a dominant role in initiating the degradation process. Hepatocytes of high viability degrade insulin in direct proportion to the mass of insulin bound to the cell $[1,2]$; receptor-mediated degradation has been observed in adipocytes [3] and the demonstration of receptor-mediated endocytosis of the insulin-receptor complex has provided a mechanism by which this may occur [4]. Studies in vivo have shown a close correlation between the metabolic clearance rates of chemically-modified insulins and their abilities to induce a biological effect [5], again suggesting a common specific recognition site for the two processes.

It follows that experimental observations concerning the distribution and metabolism of insulin in human subjects include information about the status of insulin receptor sites. To derive this information it is necessary to construct a hypothetical mathematical model to analyse the data.

Hitherto both simple [6] and comprehensive [7, 8] models of insulin distribution and metabolism, while satisfactorily predicting time-courses of insulin concentration in the plasma compartment, have in general lacked parameters which represent well-recognised bio- chemical processes such as receptor binding. Validation of these models has either required such simplicity of structure as to allow a relatively unambiguous estimation of the parameters, which can then be validated statistically, or has relied upon the ability accurately to predict rates of change of concentration of plasma insulin during various infusion protocols [8]. Recognition that insulin receptors may play a major role in initiating degradation of the ligand [1-5] allows incorporation of the known features of insulin receptor function [9] into systems of interpretation of data obtained in vivo. At least one previous complex model has included receptor compartments [10]. We report here that construction of a simple model including these features permits a further approach to validation by direct comparison with values of receptor kinetics derived from studies in vitro, and provides otherwise unobtainable indications of receptor status in the intact human subject.

\section{Subjects and methods}

\section{Subjects and Protocol}

Data for parameter estimation were taken from experiments involving infusion of monocomponent human insulin into ten normal volunteers. The full details of these studies and a non-compartmental analysis of the results have been reported [11]. In brief, subjects were fasted overnight. Insulin (monocomponent human, Novo, Copenhagen) was infused into an antecubital vein and blood samples taken from the contralateral arm. Serum concentrations were estimated by ra- 


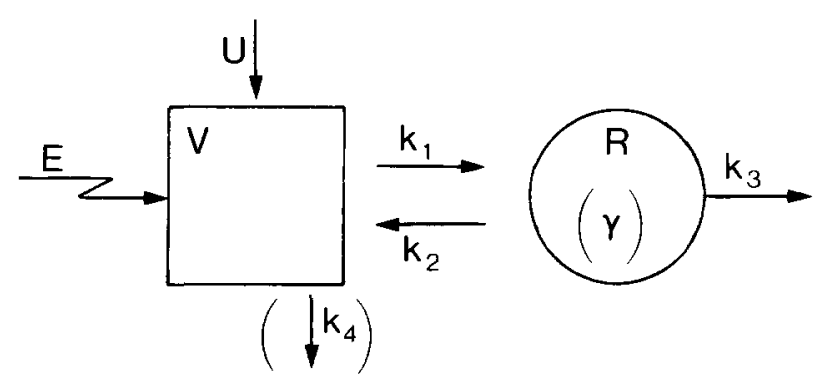

Fig. 1. Diagrammatic model structure. The distribution volume $\mathrm{V}$ includes plasma volume and is therefore the accessible site for sampling and peripheral infusion. $\mathrm{E}\left(\mathrm{nmol} \cdot \mathrm{min}^{-1}\right)$ represents delivery of endogenous insulin into this distribution space, i.e. its value will comprise entry into the plasma at the hepatic vein level, rather than pancreatic secretion. $R$ (nmol) is a population of specific potentially reversible binding sites for insulin. The rate constants $\mathrm{k}_{1}\left(\mathrm{nmol}^{-1}\right.$. $\left.\min ^{-1}\right)$ and $\mathrm{k}_{2}\left(\mathrm{~min}^{-1}\right)$ define the association and dissociation respectively of insulin to this receptor population. $\mathrm{k}_{3}\left(\mathrm{~min}^{-1}\right)$ defines the rate of irreversible removal of receptor bound insulin from the system. The need for two further parameters has been assessed: $k_{4}\left(\mathrm{~min}^{-1}\right)$ accommodates linear sites of insulin loss, e.g. to include glomerular filtration and non-specific peptide clearance pathways. $\gamma$ is a negative cooperativity factor (when $\gamma=>1$ the system includes negative cooperativity) $[13,14]$, for equations see text. At the physiological insulin levels provided by the data no statistical advantage in the fit of the model was obtained by the addition of $\mathrm{k}_{4}$ or of negative cooperativity. In the results presented $\mathrm{k}_{4}=0$ and $\gamma=1$

dioimmunoassay $[11,12]$. After baseline sampling a priming dose initiated the infusion period. Every $30 \mathrm{~min}$ a further priming dose was followed by a doubling of the infusion for a total of $2 \mathrm{~h}$. At the end of this time, infusion was stopped and sampling continued for a further $30 \mathrm{~min}$. Insulin administration rates were such as to produce a series of steady-state concentrations spanning the physiological range, followed by a complete decay curve.

In three of the 10 subjects data were incomplete due to difficulties with blood sampling. Results from the seven remaining experiments have been simulated by the model, both individually and as grouped data, to estimate the model parameters.

\section{Data Analysis}

The structure of the model is shown in Fig. 1. The differential equations describing the system are given in 1.

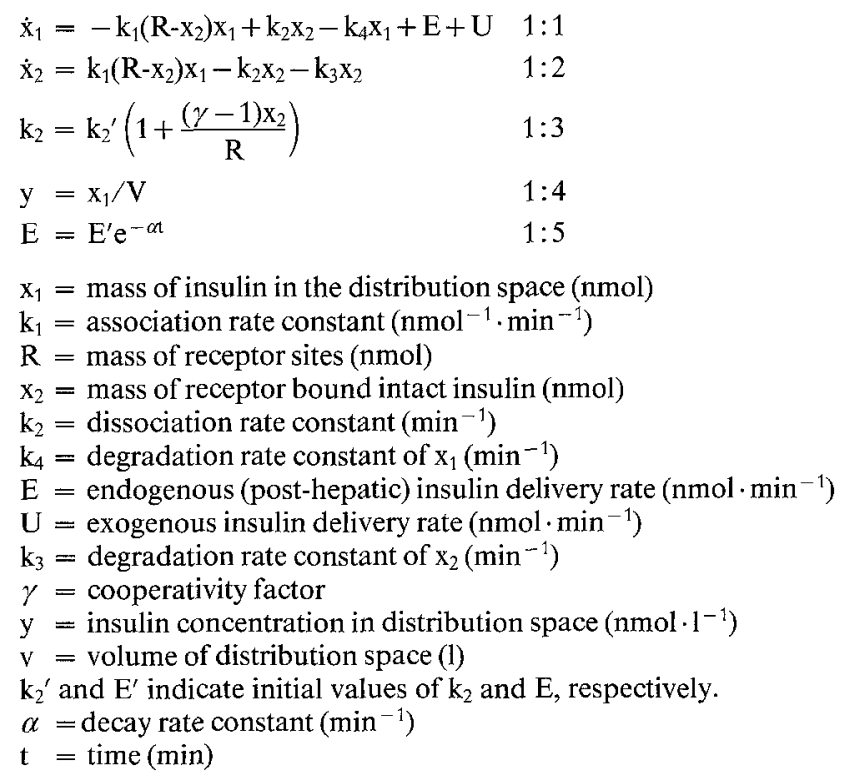

$\mathrm{x}_{1}=$ mass of insulin in the distribution space (nmol)

$\mathrm{k}_{1}=$ association rate constant $\left(\mathrm{nmol}^{-1} \cdot \mathrm{min}^{-1}\right)$

$\mathrm{R}=$ mass of receptor sites (nmol)

$\mathrm{x}_{2}=$ mass of receptor bound intact insulin (nmol)

$\mathrm{k}_{2}=$ dissociation rate constant $\left(\mathrm{min}^{-1}\right)$

$\mathrm{k}_{4}=$ degradation rate constant of $\mathrm{x}_{1}\left(\mathrm{~min}^{-1}\right)$

$\mathrm{E}=$ endogenous (post-hepatic) insulin delivery rate $\left(\mathrm{nmol} \cdot \mathrm{min}^{-1}\right)$

$\mathrm{U}=$ exogenous insulin delivery rate $\left(\mathrm{nmol} \cdot \mathrm{min}^{-1}\right)$

$\mathrm{k}_{3}=$ degradation rate constant of $\mathrm{x}_{2}\left(\mathrm{~min}^{-1}\right)$

$\gamma=$ cooperativity factor

$\mathrm{y}=$ insulin concentration in distribution space $\left(\mathrm{nmol} \cdot 1^{-1}\right)$

$\mathrm{v}=$ volume of distribution space (l)

$\mathrm{k}_{2}{ }^{\prime}$ and $\mathrm{E}^{\prime}$ indicate initial values of $\mathrm{k}_{2}$ and $\mathrm{E}$, respectively.

$\alpha=$ decay rate constant $\left(\min ^{-1}\right)$

$\mathrm{t}=\operatorname{time}(\min )$

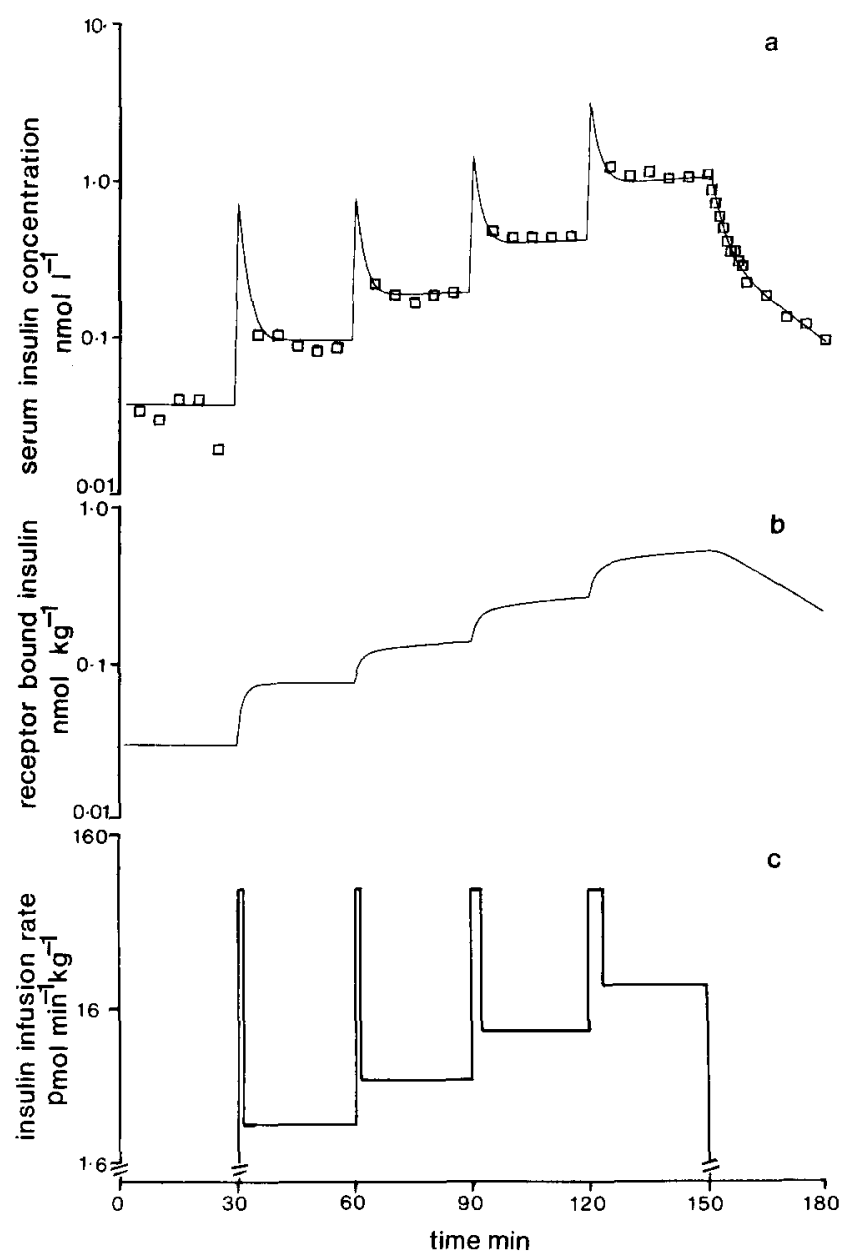

Fig. 2. Model simulation of one set of experimental data. a: model fitted line after optimisation of parameters, representing the time course of insulin concentrations in the accessible pool (V). $\square$ : measured values. b: content of receptor pool $\left(\mathrm{x}_{2}\right)$ : c: experimental input, i.e.: exogenous insulin infusion rate

$\dot{\mathrm{x}}_{1}$ and $\dot{\mathrm{x}}_{2}$ are the rates of change of the masses of free and bound insulin respectively. Equations $1: 1$ and $1: 2$ represent a first-order reversible reaction (Law of Mass Action), with the addition of $\mathrm{k}_{4}$, a linear elimination pathway, and $k_{3}$, receptor-mediated degradation. Equation $1: 3$ incorporates a factor $\gamma$ which permits the introduction of negative cooperativity $[13,14]$. In these experiments plasma glucose was allowed to fall unchecked and endogenous insulin falls rapidly after the start of the infusion [15]. Equation 1:5 accommodates this observation and $\alpha$ is empirically ascribed the value $2.5 \mathrm{~min}^{-1}$. From the end of the first infusion period $\mathrm{E}$ is ascribed the value zero.

This model is not formally identifiable in the sense that no unique algebraic solution is possible $[16,18]$. To evaluate the parameters we have used an iterative procedure, a minimisation algorithm [19] implemented on a CDC 7600 Computer. The model parameters $k_{1}, k_{2}, k_{3}, \mathbf{R}$ and $V$ were optimised for the minimum sum-of-squares error of $\log _{e}$ of the data from the beginning of the second infusion period. Although the model is not strictly identifiable, the relatively small number of parameters allows assessment by sensitivity analysis, in that alteration of each individual parameter results in a distinct pattern of model response (data not shown). Inclusion of $\mathrm{k}_{4}$ and $\gamma$ as variables within the iterative procedure increases ambiguity in accurately ascribing a value to the other parameters. For this reason the optimisation was conducted with predefined values for $k_{4}$ and $\gamma$. After derivation of the model parameters, these and the known mean basal plasma insulin concentrations were used to calculate a value for the basal endogenous insulin delivery rate at the hepatic vein level $(E)$. 
Table 1. Results for individual subjects and grouped data

\begin{tabular}{|c|c|c|c|c|c|c|c|}
\hline Subject & $\begin{array}{l}\text { Wt } \\
(\mathrm{kg})\end{array}$ & $\begin{array}{l}\mathrm{V} / \mathrm{Wt} \\
\left(\mathrm{l} \cdot \mathrm{kg}^{-1}\right) \times 10^{3}\end{array}$ & $\begin{array}{l}\mathrm{k}_{1} \\
\left(\mathrm{nmol}^{-1}\right. \\
\left.\min ^{-1}\right) \times 10^{3}\end{array}$ & $\begin{array}{l}\mathrm{k}_{2} \\
\left(\min ^{-1}\right)\end{array}$ & $\begin{array}{l}\mathrm{k}_{3} \\
\left(\min ^{-1}\right)\end{array}$ & $\begin{array}{l}\mathrm{R} / \mathrm{Wt} \\
\left(\mathrm{nmol} \cdot \mathrm{kg}^{-1}\right)\end{array}$ & $\begin{array}{l}\mathrm{E} \\
\left(\mathrm{nmol} \cdot \min ^{-1}\right) \times 10^{3}\end{array}$ \\
\hline 2 & 62 & 43.9 & 36.8 & 0.032 & 0.063 & 0.53 & 73 \\
\hline 3 & 55 & 27.3 & 15.7 & 0.023 & 0.053 & 1.15 & 22 \\
\hline 4 & 47 & 70.2 & 7.9 & 0.014 & 0.036 & 1.61 & 53 \\
\hline 7 & 73 & 63.9 & 4.9 & 0.040 & 0.070 & 1.32 & 28 \\
\hline Grouped data & $64.1 \pm 12.4$ & $58.1 \pm 8.33$ & $8.59 \pm 0.16$ & $0.019 \pm 0.002$ & $0.049 \pm 0.008$ & $1.00 \pm 0.05$ & $37.0 \pm 19.0$ \\
\hline
\end{tabular}

Parameter values derived by model optimisation are shown. To establish mean parameter estimates for the whole group of subjects the data from all seven experiments were pooled and subjected to a further full simulation. These values are shown against "grouped data". Variance expressed as one standard deviation from the optimised value was derived by use of the Hessian matrix which was evaluated using forward differences [19], except for Wt and $\mathrm{E}$ where the mean of the individual values $+1 \mathrm{SD}$ are given.
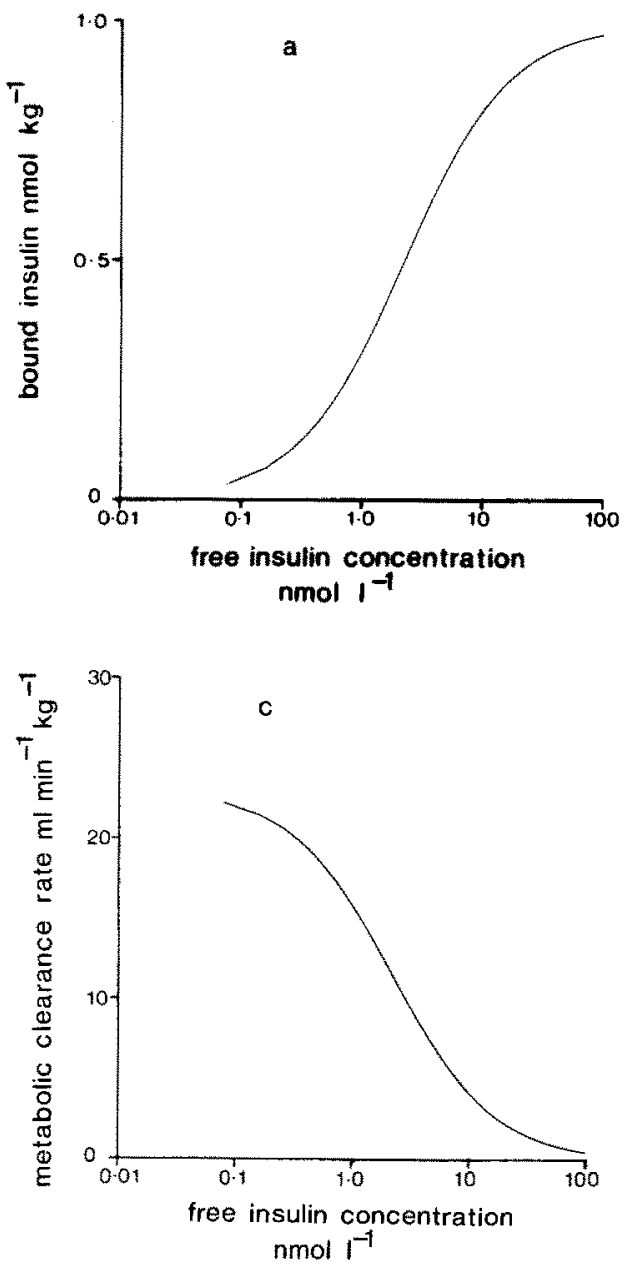

\section{Results}

Figure 2 shows an example of the model simulation of one set of data. Figure 2 a demonstrates the ability of the model to accommodate rapidly changing insulin concentrations within the physiological range, and Figure $2 b$ the ability to derive a prediction of the receptor bound insulin within the system, a value which is otherwise inaccessible. Results of simulations of the data are shown in Table 1.

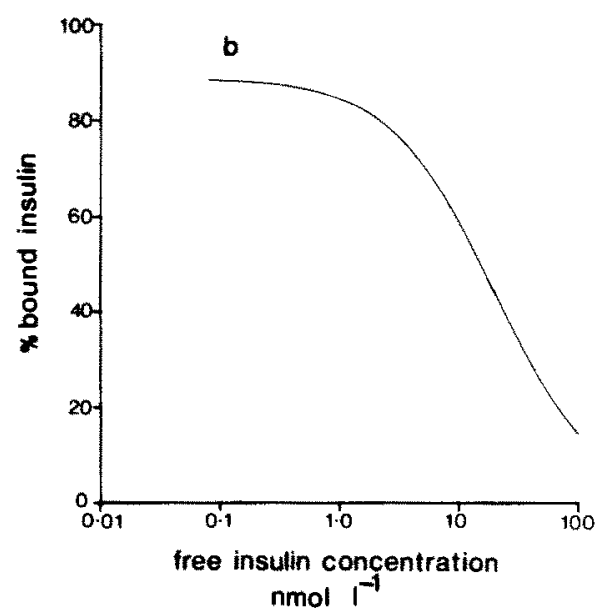

Fig. 3. Parameter values derived from an optimised simulation of the pooled data from all seven normal subjects (Table 1) have been used to simulate hypothetical experiments in which insulin is infused to equilibrium over a wide range of concentrations $\left(0.1-100 \mathrm{nmol} \cdot 1^{-1}\right)$. a: confirms the conclusion in vitro that in the physiological range of insulin concentrations $\left(0.02-2.0\right.$ nmol $\left.\cdot 1^{-1}\right)$ only a small proportion of the total receptor population is occupied [23] and illustrates for the first time estimates of absolute value for the number of receptors occupied over that range. $b$ : demonstrates that under equilibrium conditions more than $80 \%$ of intact insulin in the system is receptor-bound. c: illustrates extrapolation of insulin metabolic clearance rate. Its tendency to fall over the physiological range which has been previously reported [11] is well shown, i.e. the saturable element of insulin degradation can be accommodated by the increasing receptor occupancy. The fall to low levels at the higher insulin concentrations examined would be reduced by ascribing a value to $\mathrm{k}_{4}>0$. $\mathrm{d}$ : shows the linear Scatchard plot [28] expected with $\gamma=1$. bound insulin

\section{Discussion}

The possible rôle of abnormalities of receptor function in obesity and diabetes is of great interest. Useful but limited information has been derived from studies of the circulating erythrocytes and monocytes in groups of subjects, and from small samples of subcutaneous adipose tissue $[20,21]$. A method of evaluation which provides an integrated view of insulin receptor function in the intact organism could significantly improve our un- 
derstanding of the physiology of insulin and of the mechanisms of disorder in disease states. An opportunity for such an evaluation arises from the realisation that insulin metabolism is largely mediated by processes for which receptor recognition of the ligand provide an initial and rate limiting step.

We have derived initial quantitative estimates of receptor number and affinity from data obtained in vivo in a group of normal subjects. The construction of a model sufficiently simple to allow relatively unambiguous solution of the parameters has allowed some validation of its assumptions by comparison with available observations in vivo and in vitro. It should be emphasized that the parameter values derived for each individual data-set (Table 1) are the optimal values for the model and do not necessarily imply significant differences between subjects. For example, data-set number 5 is best described with a relatively low value for $k_{1}$ and high value for $\mathrm{R}$, while the reverse is true for data-set 2 . This shift of balance between one parameter and another is likely to derive from inescapable variance within the data and should not be regarded as indicating a range of true values in normal subjects. As with many analyses of biological observations, pooling of experiments and statistical assessment must be applied in order to ascribe confidence limits to the parameter estimations.

Graphical analysis of insulin data obtained in vivo has produced values of $83 \mathrm{ml} \cdot \mathrm{kg}^{-1}$ [11] for insulin distribution volume. This method is likely to produce overestimates on the false assumption that the system is linear. We suggest that the value for $\mathrm{V}$ reported here $\left(58.1 \mathrm{ml} \cdot \mathrm{kg}^{-1}\right)$ is based on more realistic assumptions and likely to be more accurate. It compares with a plasma volume of $27.6-53.7 \mathrm{ml} \cdot \mathrm{kg}^{-1}$ [22], with in addition a proportion of extracellular space.

The model parameter $\mathrm{k}_{1}\left(\mathrm{nmol}^{-1} \cdot \min ^{-1}\right)$ is the constant governing the rate of insulin receptor association. $\mathrm{V} \times \mathrm{k}_{1}\left(1 \cdot \mathrm{nmol}^{-1} \cdot \mathrm{min}^{-1}\right)$ is analogous to receptor "on rates" from experiments in vitro. Optimised $\mathrm{V} \times \mathrm{k}_{1}$ produces a value of $0.0321 \cdot \mathrm{nmol}^{-1} \cdot \mathrm{min}^{-1}\left(3.20 \times 10^{7}\right.$ $1 \cdot \mathrm{mol}^{-1} \cdot \mathrm{min}^{-1}$ ) for the grouped data with a range of $0.7 \times 10^{7}$ to $10.03 \times 10^{7} 1 \cdot \mathrm{mol}^{-1} \cdot \mathrm{min}^{-1}$ for the individual subjects. Published values for the rate constant of association of insulin with its receptor at $37^{\circ} \mathrm{C}$ are $2.5 \times 10^{7}$ and $23 \times 10^{7} 1 \cdot \mathrm{mol}^{-1} \cdot \mathrm{min}^{-1}[23,24]$. The value for $\mathrm{k}_{2}+\mathrm{k}_{3}, 0.068 \mathrm{~min}^{-1}$ for the grouped data, can be compared to the rate constant of dissociation of insulin from its receptor in in vitro systems, 0.07 and $0.12 \mathrm{~min}^{-1}$ $[23,24]$. Receptor-mediated degradation has been measured in intact hepatocytes and the governing rate-constant reported to be $0.03 \mathrm{~min}^{-1}$ [1] and $0.028 \mathrm{~min}^{-1}$ [2]. These results compare well with our own model-derived values (Table 1).

The expression $\left(\mathrm{k}_{2}+\mathrm{k}_{3}\right) /\left(\mathrm{V} \times \mathrm{k}_{1}\right)$ is equivalent to the dissociation constant $K_{d}$ derived from equilibrium experiments in vitro. The model-derived value for this variable, $2.13 \mathrm{nmol} \cdot 1^{-1}$ for the grouped data, is in good agreement with published estimates, 0.4 to $4.2 \mathrm{nmol} \cdot 1^{-1}$ [23-25]. Parameter estimations with predefined values of $\mathrm{k}_{4}>0$ (i.e. with the addition of a non-receptor-mediated degradation pathway), or with $\gamma>1$ (i.e. with the inclusion of negative cooperativity), resulted in no statistically significant improvement in the goodness of fit of the model to the data (F-test). On this basis, for the results presented, $\mathrm{k}_{4}=0$ and $\gamma=1$. With high receptor occupancy requiring faster infusion rates than those used here, values for these parameters should be become susceptible to estimation and comparison with other observations.

Estimates of basal endogenous post-hepatic insulin delivery rates have been reviewed [26]. Values normalised for a $70-\mathrm{kg}$ subject range from 3.84 to $10.48 \mathrm{mU} \cdot \min ^{-1}\left(25.6\right.$ to $\left.69.9 \mathrm{pmol} \cdot \mathrm{min}^{-1}\right)$. Our own estimates $\left(22\right.$ to $\left.73 \mathrm{pmol} \cdot \mathrm{min}^{-1}\right)$ are in excellent accord with these published values.

Unique to this model is the ability to estimate accessible insulin receptor number in the intact individual $\left(1.0 \pm 0.05 \mathrm{nmol} \cdot \mathrm{kg}^{-1}\right.$ for the grouped data). This value once obtained allows examination of further previously unknown values. For example, the absolute quantities of insulin bound to receptor sites at equilibrium over a range of physiological free-insulin concentrations, and hence the relative proportions of free and receptorbound insulin (Fig. 3).

We have established that a simple two-compartment model of insulin distribution and metabolism is capable of accommodating the non-linearity of insulin data if the second compartment incorporates the known mechanisms of receptor involvement in insulin degradation. Modification of the model by dividing the receptor compartment and the distribution space into two (hepatic and peripheral, portal and systemic) would with appropriate data allow access to values for pancreatic insulin secretion, portal insulin concentrations and hepatic insulin status.

With suitable data, i.e. where receptor occupancy is greater, the model provides for the quantitation of the linear non-receptor-mediated pathways of insulin removal, and estimation of the magnitude (if any) of the effect of increasing receptor occupancy on dissociation rate (negative cooperativity). More complex models could be constructed to allow for reversible isomerisation of the insulin receptor complex, for example, or for the possible contribution of growth-factor receptors as binding sites for insulin. Such modifications would involve the incorporation of an increasing number of parameters inaccessible to comparison in vitro. The aim of this study was to assess the ability of a relatively simple mathematical structure to generate physiologically useful information. The preliminary observations described here offer opportunities for assessment of receptor function in diseased states and for a more sophisticated analysis of the behaviour of insulin analogues in vivo. Receptor-mediated internalisation occurs for many ligands other than insulin [27], and the 
principles applied here should be of wide application in endocrinology and pharmacology.

Acknowledgements. We thank the Department of Community Medicine, St Thomas' Hospital for provision of computing facilities and S Gunnell and LMLawrence for help with the manuscript. The research was supported by a grant from the St Thomas' Hospital Research Endowment Fund.

\section{References}

1. Terris S, Steiner DF (1975) Binding and degradation of ${ }^{125}$ I-insulin by rat hepatocytes. J Biol Chem 250: 8389-8398

2. Juul SM, Jones RH (1982) Evidence for direct effect of bacitracin on cell-mediated insulin degradation in isolated hepatocytes. Biochem J 206: 295-299

3. Gliemann J, Sonne O (1978) Binding and receptor-mediated degradation of insulin in adipocytes. $\mathrm{J}$ Biol Chem 253: 7857-7863

4. Carpentier JL, Gorden P, Le Cam A, Freychet P, Orci L (1977) Limited intracellular translocation of ${ }^{125}$ I-insulin in isolated rat hepatocytes. Diabetologia 13:386

5. Papachristodoulou D, Brandenburg D, Dron DI, Jones RH, Sönksen PH, Thomas JH (1977) Studies on the relationship between the molecular structure and the catabolism of insulin. Acta Biol Med Ger 36: 1705-1712

6. Insel PA. Liljenquist JE, Tobin JD, Sherwin RS, Watkins $P$, Anders R and Berman M (1975) Insulin control of glucose metabolism in man. J Clin Invest 55: 1057-1066

7. Tiran J, Avrach LI, Albisser AM (1979) A circulation and organ model for insulin dynamics. Am J Physiol 237 (47): E331-E339

8. Cobelli C, Gederspil G, Pacini G, Salvan A, Scandellari C (1982) An integrated mathematical model of the dynamics of blood glucose and its hormonal control. Math Biosci 58: 27-60

9. Kahn CR (1976) Membrane receptors for hormones and neurotransmitters. J Cell Biol 70: 261-286

10. Berman M, McGuire EA, Roth J, Zeleznik AJ (1980) Kinetic modelling of insulin binding to receptors and degradation in vivo in the rabbit. Diabetes $29: 50-59$

11. Sönksen PH, Tompkins CV, Srivastava MC, Nabarro JDN (1973) A comparative study on the metabolism of human insulin and porcine proinsulin in man. Clin Sci Mol Med 45: 633-654

12. Morgan CR, Lazarow A (1962) Immunoassay of insulin using a two-antibody system. Proc Soc Exp Biol Med 110: 29-32

13. De Meyts P, Bianco AR, Roth J (1976) Site-site interactions among insulin receptors: characterisation of the negative cooperativity. J Biol Chem 251: 1877-1888

14. De Lean, A Rodbard D (1980) Kinetic analysis of co-operative ligand binding: application to the insulin receptor. Fed Proc 39: $116-120$
15. Frost DP, Srivastava MC, Jones RH, Nabarro JDN, Sönksen PH (1973) The kinetics of insulin metabolism in diabetes mellitus. Postgrad Med J 49 (December suppl): 949-954

16. Pohjanpalo H (1978) System identifiability based on power series expansion of the solution. Math Biosci 41: 21-34

17. Cobelli C, DiStefano JJ III (1980) Parameter and structural identifiability concepts and ambiguities, a critical review and analysis. Am J Physiol 239: R7-R24

18. Godfrey KR, Jones RP, Brown RF, Norton JP (1982) Factors affecting the identifiability of compartmental models. Automatica $183: 285-293$

19. Gill PE, Murray W (1976) Minimisation subject to bound on the variables. National Physical Laboratory Report No. NAC 72. Her Majesty's Stationery Office, London

20. Gavin JR III, Roth J, Jen P, Freychet P (1972) Insulin receptors in human circulating cells and fibroblasts. Proc Natl Acad Sci USA 69: $747-751$

21. Pederson O, Hjollund $\mathrm{E}$ (1982) Insulin receptor binding to fat and blood cells and insulin action in fat cells from insulin-dependent diabetics. Diabetes 31: 706-715

22. Diem K (ed) (1962) Documenta Geigy Scientific Tables, Sixth Edition. JR Geigy, Basle, Switzerland p 547

23. Gammeltoft S, Gliemann J (1973) Binding and degradation of ${ }^{125} \mathbf{I}$ insulin by isolated fat cells. Biochim Biophys Acta 320: 16-32

24. Gammeltoft S, Kristensen LO, Sestoft L (1978) Insulin receptors in isolated rat hepatocytes. Reassessment of binding properties and observations of the inactivation of insulin at $37^{\circ} \mathrm{C}$. J Biol Chem 253: 8406-8413

25. Foley JE, Laursen AL, Sonne O, Gliemann J (1981) Insulin binding and hexose transport in rat adipocytes. Relation to cell size. Diabetologia 19: 234-241

26. Eaton RP, Allen RC, Schade DS, Erikson KM, Standefer J (1980) Prehepatic insulin production in man: kinetic analysis using peripheral connecting peptide behaviour. J Clin Endocrinol Metab 51: $520-528$

27. Goldstein JL, Anderson RGW, Brown MS (1979) Coated pits, coated vesicles, and receptor-mediated endocytosis. Nature 279: 679-685

28. Scatchard G (1949) The attractions of proteins for small molecules and ions. Ann NY Acad Sci 51: 660-672

Received: 7 June 1983

and in revised form: 14 May 1984

Dr. R. H.Jones

Medical Unit

St. Thomas' Hospital Medical School,

London SE1 7EH

UK

0050A/1074A 